Revista Brasileira de Odontologia Legal - RBOL

\title{
Entrevista / Interview
}

\section{Profa. Dra. ELIDA NORMA BRIÑÓN}

Informação sobre o artigo

Realizada em: 03 Novembro 2015

\section{Contacto}

Dra. Elida Norma Briñón

Buenos Aires, Argentina.

brinon_elida_legalyforense@yahoo.com.ar

\section{CURRICULUM VITAE (RESUMIDO)}

- Asesora en Odontología Legal y Forense - Dra. en Odontología - UBA*.

- Especialista en Ortodoncia con Odontología Legal - UBA.

- Especialista en Cirugía dento-maxilar - UBA.

- Licenciada en Criminalística - UBA (Fac. de Derecho y Ciencias Sociales).

- Laurea. In "Odontoiatria e Protesi Dentaria" Siena - Itália (graduación: 110 e LODE).

- Premio Facultad de Odontología al mejor trabajo de investigación. "La Pericia Odontolegal".

- Perito de Oficio en los Fueros Civil, Penal y Laboral.

- Prof. Titular "Odontología Legal y sanitaria - UAI.

- Testimonio como odontóloga en El Tribunal de Roma en la causa CVL, por lesiones estomatológicas en Implatología.

- Conferencista nacional e internacional. Dictante de cursos Nacionales y Extranjeros.

- Autora de dos libros en materia: "Odontología Legal y Práctica Forense", Editora Purinzon, 1982; y "Lesiones e latrogenias en Odontología Legal", Cathedra Jurídica. 2006.

- Directora y asesora científica. Miembro de la Asociación Civil Argentina de Odontología Social, Sanitaria, Legal y Forense. Fundadora de Asociaciones Odontológicas en: Trieste, Pordenone y Milán (Italia).

- Presidente Honorífico de la A.O.F.S.

- Ex Docente de las Cátedras de Ortodoncia con Odontología Legal y Antropología Filosófica. UBA.

- Odontóloga del Hospital Fiorito y Asistencia Pública.

- Intercambio recíproco de técnicas criminalísticas con Interpol (Roma): Saint Cloud, París Francia- Lyon- Roma.

- Ejercicio privado de la profesión.

- Nombramiento profesional como titular para presidir el Jurado de selección por antecedentes y oposición al cargo de Perito Oficial de la Suprema Corte de Justicia Nacional (Especialidad en Odontología Forense).2014

- Autora del libro "Autopsias médicas y odontológicas del sistema estomatognático": En prensa).

*UBA - Universidad Buenos Aires, Argentina. 
(1) Como decidió ingresar al campo de actuación de la Odontología Legal?

Me interesaba la Ortopedia Funcional de los maxilares, como especialidad, ello me llevó a ingresar en la especialidad de "Ortodoncia con Odontología Legal" (UBA). Entré como ayudante en la Cátedra, luego lo hice como Jefa de trabajos prácticos, al poco tiempo comencé a actuar como perito odontóloga en los Fueros: Laboral, Civil y Penal. Se dio el caso que el Juez Dr. Carlos Ure, del Juzgado en lo Criminal. Secretaría No.114, (1971), solicitó al Rectorado un profesional en Odontología Forense, se derivó el pedido a la Cátedra de Ortodoncia con Odontología legal, titular de la Cátedra Prof. Dr. Armando Monti (UBA). En ese tiempo no existía la especialidad en Odontología Forense, tarea que desempeñaban los médicos forenses. A tal efecto recibí la citación del Dr. C. Ure, para efectuar un informe pericial.

El caso se trataba de la exhumación de un cadáver NN. hallado en el río, al cual le habían practicado ya dos autopsias, ambas incompletas, sin resultado. Hasta el momento era un NN. Realizadas las pericias

del sistema estomatognático al NN. Logrado el objetivo de identificar el cadáver, recibí las felicitaciones $y$ agradecimiento del Juez Dr C. Ure, que lo cursó a la Universidad. Finalizada las pericias llegué a la conclusión que debía poseer mayores conocimientos del lenguaje Jurídico y en especial comprender cuales eran los límites y extensión de nuestro desempeño y conocimientos, al ser ésta una labor que debía desempeñarse en colaboración y en equipo con los médicos forenses en sus distintas especialidades.

Ello me llevó a inscribirme en la Licenciatura en Criminalística dictada en la Facultad de Derecho y Ciencias Sociales (UBA) que me resultó de gran utilidad (1973). Para ampliar más el campo entré en la Cátedra de Cirugía Dento-maxilar, en donde cursé la Especialidad, con el objeto de considerar otros aspectos anatómicos, traumatismos, lesiones y sus consecuencias (UBA - 1973)

A partir de ese momento decidí ampliar los conocimientos ya existentes en materia, escribir mis experiencias, indicaciones $y$ observaciones que se presentaron 
durante la actuación como perito en los distintos Fueros, y para que sirvieran de guía no sólo para mi sino también a quien quisiera consultarlos, de ahí la publicación del libro "Odontología legal y Práctica Forense" (1982 - ed. Purinzón - Argentina).

Es importante participar, transmitir e intercambiar ideas de técnicas y procedimientos que hacen al quehacer profesional en esta especialidad, porque de ahí surgen modificaciones y mejoras.

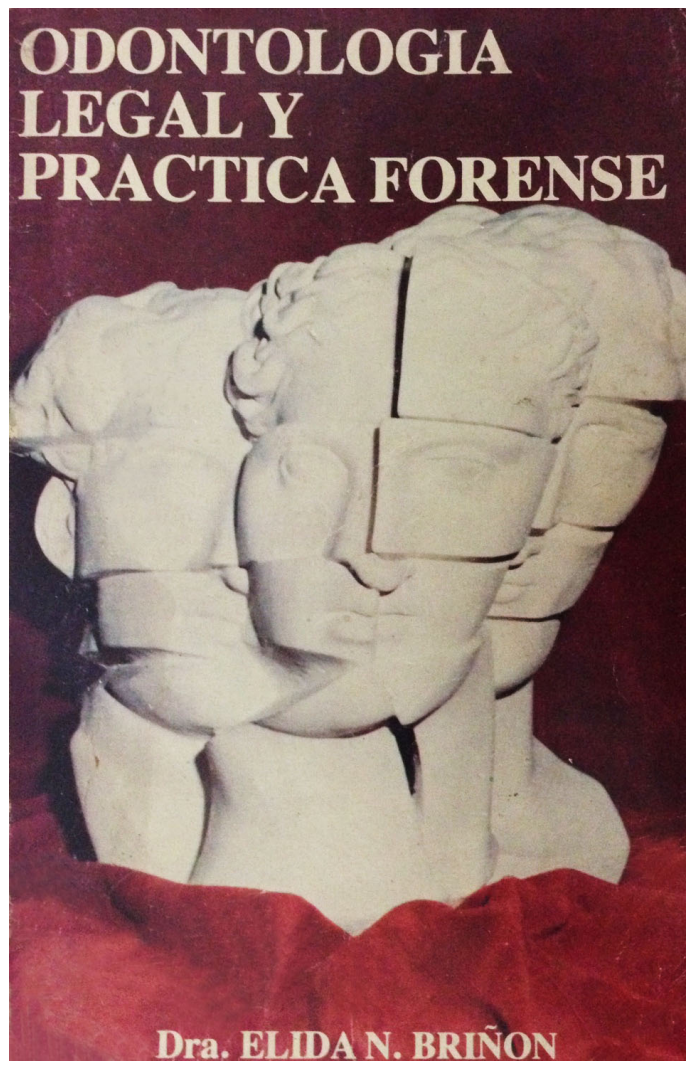

Figura 1 - Odontología legal y Práctica Forense (1982).
(2) En su país, Argentina, cómo ve el desarrollo de la Odontología Legal?

La difusión de esta especialidad está tomando auge en nuestro país, y en base a este interés se han y se están creando estudios de post-grado universitario como especialistas en Odontología Legal y Forense, con título universitario válido para ejercer la profesión y en un futuro no lejano incorporarse con nombramiento oficial en la Justicia, al igual, como se ha hecho con otras especialidades. Por un proyecto de la Dra. Argibay se constituyó el Jurado del cual formé parte y se procedió por primera vez a nominar profesional para cubrir el cargo de Odontólogo Forense en La Corte Suprema de Justicia por Antecedentes y Oposición.

(3) Por la experiencia internacional que posee, como ve la especialidad en América del Sur?

Cuando hablamos de perfeccionamiento esto no sólo debe ser válido para los nuevos profesionales sino también para aquellos que ya la ejercen, por un lado aprovechar de sus 
experiencias vividas y por otro considerar todo aquello que aún no se hace. Por la ubicación topográfica, la actuación y aprendizaje tienen distintas características en América del Sur; cada país debe participar en todo lo posible otorgando becas de perfeccionamiento en el uso del instrumental y equipos técnicos actualizados en la investigación, aprovechando el progreso actual de la ciencia forense.

Dado el alto costo de estos equipos informáticos deben ser entidades tanto privadas como del estado las que brinden la oportunidad a los estudiosos de trabajar con ellos para igualar a países que ya disponen de estas tecnologías de investigación.

(4) Para los nuevos profesionales que se interesan por ese campo de actuación, que Usted recomienda? Cuál es la formación necesaria y cuáles son los desafíos?

En cuanto a la formación debe ser Universitaria, de post grado, y ofrecer los últimos adelantos en materia, para que desde el inicio de los estudios ya se vean vinculados y comprometidos con los conocimientos necesarios para poder desempañarse con exactitud y sin dudas; ya que en esta especialidad no se admiten ni errores ni omisiones en las informaciones.

Saber más que los propios delincuentes, dar veracidad de los hechos y verificación de la verdad, apreciación de procedimientos, amplio cumplimiento del deber y obligaciones en la actuación profesional abalados por títulos universitarios: estos conocimientos nos ponen en condiciones de aceptar un desafío.

(5) Cuáles son los casos de relevancia nacional e internacional de la Odontología Legal que actuó?

$\mathrm{Ya}$ he mencionado en precedencia el trabajo desempeñado como perito en nuestro país. En el ámbito internacional, por ejemplo en Italia, me desempeñé como asesora de abogados en diversas causas civiles y laborales que me sirvió de ejemplo para conformar la lista de baremos actualizando los valores siguiendo el lineamento europeo.

A pesar de tener el título de "Dottssa. in Odontoiatria e protesi 
dentaria”, obtenido en la Universidad de Siena (Italia) con la máxima calificación, actué como consultora de abogados y no como perito, debido a que el idioma italiano, posee un lenguaje jurídico que es muy florido, no así su contenido por ser sus leyes semejantes a las de Argentina. Mi actuación fue como testimonio y asesora en causas legales.

En Italia tuve oportunidad de desempeñar el cargo de profesora en Anatomía, Histología y Fisiología, materias que se dictan juntas por asociación de conceptos. Los dos libros escritos por mí en castellano, fueron difundidos en Europa. Cabe mencionar que el Dr. Italo Robetti, y su equipo, de la Cátedra de Odontología del Hospital de La Moulinet de Turin (Italia), al mismo tiempo publicó un libro semejante al que yo escribiera, con la misma orientación y contenido, lo extraño fue que no nos conocíamos ni teníamos referencias de nuestros trabajos, ello me causó satisfacción de pensar que estábamos en el mismo proyecto, escribir sobre el mismo tema nos demuestra la necesidad de querer saber más en dicho campo, que en resumidas cuentas no es más que una necesidad de un país que no se detiene en sus actualizaciones.

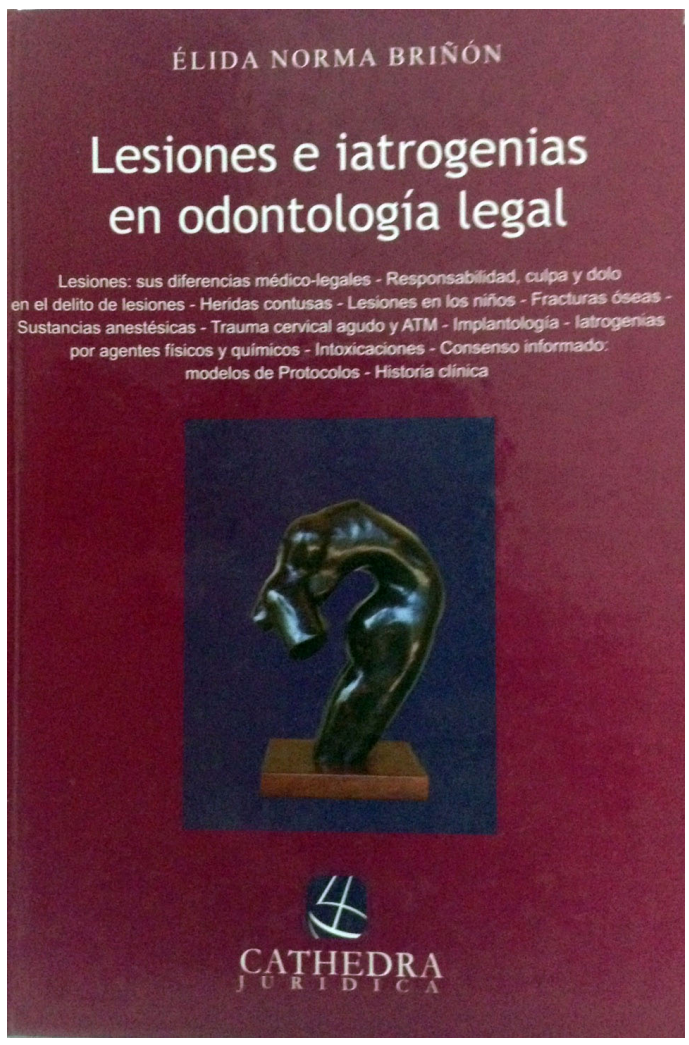

Figura 2 - Lesiones e latrogenias en Odontología Legal (2006).

(6) En el campo de la valoración del daño corporal, cuáles son los desafíos para el especialista en Odontología Legal en ese tipo de actuación?

Cuando se refiere a la evaluación civil o en el área del trabajo, si se trata de lesiones es conveniente basarse en baremos de evaluación, propuesto por cada país donde se actúa, los baremos constituyen una guía de orientación, es una escala convencional pero no obliga al Juez a aceptarlo tal cual está escrito. 
Establecido el daño, es el Juez que evalúa el daño biológico y el lucro cesante. Cuando se habla de delito de lesiones es el Juez quien define el tipo de delito que se ha cometido de acuerdo a lo especificado por los Códigos y se le asigna una culpa o no, según se trate.

La actuación por parte del odontólogo que desea especializarse debe ser tanto en la parte legal como en la forense, la primera concierne al área civil y de trabajo, la segunda es el reconocimiento de los daños causados sobre una persona y sus consecuencias: en estos casos se trata de delitos de lesiones provocadas con la intención de hacer mal a otro o producidas por actitudes involuntarias, competencia del Fuero Criminal.

Poseer el título habilitante de Odontólogo Forense no significa la sustitución de la actuación médicoforense, representa un hecho importante cuando se trabaja en equipo, donde se comparten nuevas experiencias y conocimientos por parte de los integrantes de la ciencia legal y forense, la mejor demostración de ello es compartir la investigación y apreciación en el lugar del hecho de las pruebas que encuentran del sistema estomatognático.

Si se tratase de evaluar el grado de las lesiones inferidas con repercusión en el órgano de la masticación, ocurrido en un lugar de trabajo, si existiese un desacuerdo entre las partes donde intervienen las compañías aseguradoras, el perito oficial experto en la parte laboral, intervendrá en la evaluación de los daños producidos sin favorecer a las partes.

Otro ejemplo de intervención del perito oficial sería establecer en tiempo y forma la identidad de personas desaparecidas o porque por su estado físico o por enfermedad se ignora y son causas de repercusión social tanto civil como penal, en los cuales el sistema estomatognático nos ofrece elementos de identificación imponderables.

(7) Como autora de obras literarias que son referencias en la Odontología Legal, que piensa sobre el futuro para los campos de estudio de la Odontología Legal? 
Opino que la Odontología Legal y Forense ofrecen una colaboración positiva al cuerpo forense, se trate de: profesionales médicos, biólogos, psicólogos, patólogos, antropólogos, etc, es decir, a todos los profesionales que integran el cuerpo forense en cualquier área.

La posibilidad de recoger material en caso de identificaciones es imprescindible, ejemplo de ello son los elementos dentarios que resisten a altas temperaturas, como así los restos óseos del sistema estomatognático que permiten conocer sexo y edad aproximada; la talla por medidas antropométricas en base a las piezas dentarias; detectar en los niños si han sufrido mal trato o abuso, según su comportamiento cuando son atendidos, a causa de accidentes, la indagatoria es insustituible y debe acompañarse con la colaboración de un psicólogo.

Siempre hablando del sistema estomatognático la odontología legal y forense que es el área de nuestra especialidad; presta su colaboración en diversos aspectos en materia. Ya sea en la interpretación de accidentes, diagnósticos y pronósticos; también se ocupa de la actualización de baremos, referidos a las aseguraciones en el trabajo como consecuencia de accidentes laborales, identificación de personas, etc.

En el levantamiento de huellas por mordeduras ya sean de agresión $\mathrm{y} / \mathrm{u}$ ofensiva. En la constatación de hechos de tortura, como ser el uso de la picana eléctrica que por sus bruscos movimientos de contracción muscular ocasiona la pérdida de piezas dentarias; establecido el hecho interviene la fase de reconocimiento del daño ocasionado y de su rehabilitación futura.

Entiendo que el campo es tan amplio, que para actuar en la especialidad forense, la carrera debe poseer materias como: Cirugía. Psicología. Farmacología, Criminalística y Criminología. Radiología. Fotografía. Conocimientos del Derecho, en ámbito Civil, Penal, informática y todo aquello que exija el progreso científico, como mínimo.

Todas estas materias son indispensables a pesar de haberlas cursado para obtener el título Universitario como Odontólogo. 
La duración del aprendizaje debería tener no menos de 3 años con formación teórica y práctica. Cabe agregar que dicha formación debe ser aprobada por la CONEAU (Comisión Nacional de Evaluación y Acreditación Universitaria).

Ello es lo que se estima de llevar a cabo en la República Argentina, al igual que otros países Sudamericanos.
En América del Sur no solamente nos une el idioma, debemos estar unidos científicamente para darle al ciudadano la protección legal y humana que es merecedor.

Agradecimento ao Dr. Oscar Francisco Javier Heit pelo suporte na obtenção desta entrevista. 